\title{
Meta-analysis of the incidence and risks of interstitial lung disease and QTC prolongation in non-small-cell lung cancer patients treated with ALK inhibitors
}

\author{
Liping Lin ${ }^{1,4, *}$, Juanjuan Zhao ${ }^{2, *}$, Ning Kong ${ }^{3,4}$, Yan He ${ }^{1,4}$, Jiazhu Hu ${ }^{1,4}$, Fuxi Huang ${ }^{1,4}$, \\ Jianjun Han $^{1,4}$ and Xiaolong $\mathrm{CaO}^{1,4}$ \\ 'Department of Oncology, Panyu Central Hospital, Guangzhou, 511400, China \\ ${ }^{2}$ School of Nursing, Sun Yat-sen University, Guangzhou, 510000, China \\ ${ }^{3}$ Department of Ophthalmology, Panyu Central Hospital, Guangzhou, 511400, China \\ ${ }^{4}$ Cancer Institute of Panyu, Guangzhou, 511400, China \\ "These authors contributed equally to this work
}

Correspondence to: Liping Lin, email: linliping2017@tom.com

Keywords: ALK-TKIs, interstitial lung disease, QTC prolongation, non-small-cell lung cancer, meta-analysis

Received: April 16, $2017 \quad$ Accepted: May 03, $2017 \quad$ Published: May 29, 2017

Copyright: Lin et al. This is an open-access article distributed under the terms of the Creative Commons Attribution License 3.0 (CC BY 3.0 ), which permits unrestricted use, distribution, and reproduction in any medium, provided the original author and source are credited.

\section{ABSTRACT}

Background: To conduct a systematic review and meta-analysis to assess the overall incidence and risk of interstitial lung disease (ILD) and QTc prolongation associated with anaplastic lymphoma kinase (ALK)-tyrosine kinase inhibitors (-TKIs) in non-small-cell lung cancer (NSCLC) patients.

Results: A total of 1,770 patients from 8 clinical trials were included. The incidences of high-grade ILD and QTc prolongation was $2.5 \%$ (95\% CI $1.7-3.6 \%$ ), and $2.8 \%$ (95\% CI 1.8-4.3\%), respectively. Meta-analysis demonstrated that the use of ALK-TKIs in NSCLC patients significantly increased the risk of developing highgrade ILD (Peto OR, 3.27, 95\%CI: 1.18-9.08, $p=0.023$ ) and QTc prolongation (Peto OR 7.51, 95\% CI, 2.16-26.15; $p=0.002$ ) in comparison with chemotherapy alone.

Materials and Methods: A systematic literature search was performed to identify related citations up to January 31, 2017. Data were extracted, and summary incidence rates, Peto odds ratios (Peto ORs), and 95\% confidence intervals (CIs) were calculated.

Conclusions: The use of ALK-TKIs significantly increases the risk of developing high-grade ILD and QTc prolongation in lung cancer patients. Clinicians should pay attention to the risks of severe ILD and QTc prolongation with the administration of these drugs.

\section{INTRODUCTION}

Lung cancer remains the most commonly diagnosed cancer and the leading cause of cancer mortalities globally [1]. The majority of lung cancer (about 85\%) are classified as non-small cell lung cancer (NSCLC) [2]. In the past decade, many genomic abnormalities, such as epidermal growth factor receptor (EGFR) mutation and anaplastic lymphoma kinase (ALK) rearrangements, have been identified in NSCLC. And molecular anticancer agents targeting these genomic abnormalities provide novel treatment options for these patients [3-6]. It has been found that ALK gene-rearrangements occur in approximately $5 \%$ of patients with NSCLC [7]. Crizotinib, an oral small-molecule tyrosine kinase inhibitor against ALK, MET and ROS1 kinases, is the first approved ALKinhibitor (ALK-i) by Food and Drug Administration (FDA) as first-line treatment for ALK-positive advanced NSCLC [8]. However, acquired resistance to crizotinib by activing alternative signaling pathways usually develops within the first year of treatment. Clearly, the development of effective next-generation ALK inhibitors 
for the advanced NSCLC is desperately needed. Indeed, two next-generation ALK inhibitors ceritinib and alectinib have shown high activities in either crizotinib-pretreated or -naïve population [9-11]. As a result, the treatment landscape of ALK-positive NSCLC is expected to evolve rapidly.

In comparison with traditional cytotoxic anticancer therapies, ALK-TKIs have been reported with a unique spectrum of adverse events, although the common toxicities of ALK-TKIs, such as nausea and diarrhea, are well tolerated and manageable $[4,12,13]$. Concerns have arisen regarding the incidence and risk of interstitial lung disease (ILD) events and QTc interval prolongation with the use of ALK-TKIs, although the role of ALKTKIs in the development of these toxicities remains unknown [14]. Current recognition of its risk according to single individual trial, but these studies generally have small sample size and patient selection bias. To our best knowledge, there has been no systematic review to synthesize these data and the overall risk of these toxicities induced by ALK-TKIs hasn't been defined. Therefore, we conducted a meta-analysis and systematic review of published phase II and III clinical trials to investigate the overall risk of developing ILD and QTc prolongation in NSCLC patients treated with ALK-TKIs.

\section{RESULTS}

\section{Search results}

We initially found 210 relevant citations of ALKTKIs in NSCLC patients. After excluding review articles, phase I studies, case reports, editorial, letters, commentaries, meta-analyses and systematic review (Figure 1), we selected 8 prospective trials, included 3 phase III [15-17] and 7 phase II trials [18-22] (Table 1). A total of 1,770 patients were finally included in the present study. Table 1 listed the baseline characteristics of patients and studies. The quality of each included study was roughly assessed according to Jadad scale, and all of the three randomized controlled trials were open-label controlled trials, thus had Jadad score of 3 .

\section{Incidence and risk of ILD with ALK-TKIs}

For calculating the overall incidence of grade 3-4 ILD events, a total of 1,236 NSCLC patients were included: the events of ILD was reported in 25 out of 1,236 NSCLC patients received ALK-TKIs with an incidence of $2.5 \%$ (95\% CI: $1.7-3.6 \%$, Figure 2A). The pooled risk of developing high-grade ILD events was 3.27 (95\%CI: $1.18-9.08, p=0.023$ ) in NSCLC patients received ALKTKIs in comparison with chemotherapy alone (Figure $3 \mathrm{~A}$ ).

\section{Incidence and risk of QTc prolongation}

For calculating overall incidence of grade 3-4 QTc prolongation, there were a total of 766 patients in our analysis: the events of QTc prolongation was reported in 20 out of 766 NSCLC patients receiving ALK-TKIs yielding an overall incidence of $2.8 \%$ (95\% CI, 1.8-4.3\%, Figure 2B). The RR (fixed effect) to develop grade 3-4 QTc prolongation was $7.51(95 \% \mathrm{CI}, 2.16-26.15 ; p=$ 0.002 , Figure 3B) in NSCLC patients received ALK-TKIs in comparison with controls.

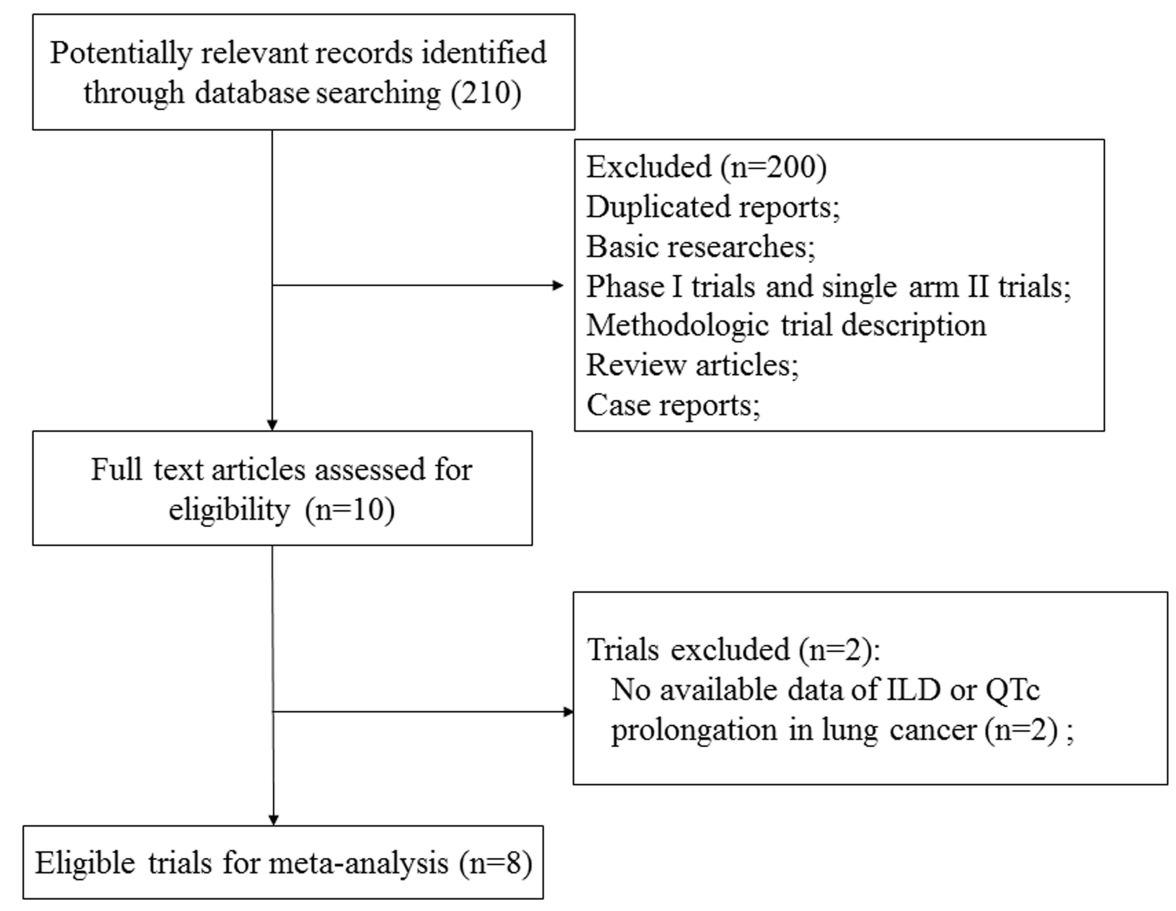

Figure 1: Flow chart of trial selection process in the meta-analysis. 
Table 1: Baseline characteristics of eight included prospective trials

\begin{tabular}{|c|c|c|c|c|c|c|c|}
\hline Authors/ year & Phase & $\begin{array}{l}\text { Patients } \\
\text { enrolled }\end{array}$ & Treatment Arm & $\begin{array}{l}\text { Median } \\
\text { age }(y)\end{array}$ & $\begin{array}{l}\text { Median } \\
\text { PFS (m) }\end{array}$ & $\begin{array}{l}\text { Median } \\
\text { OS (m) }\end{array}$ & $\begin{array}{l}\text { No. for } \\
\text { analysis }\end{array}$ \\
\hline Kwak E.L. et al/2010 & $\begin{array}{l}\text { Expansion } \\
\text { cohort }\end{array}$ & 82 & Crizotinib 250mg bid po & 51 & NR & NR & 82 \\
\hline Camidge D.R. et al/2012 & $\begin{array}{c}\text { Expansion } \\
\text { cohort }\end{array}$ & 149 & Crizotinib 250mg bid po & 52 & 9.7 & NR & 149 \\
\hline \multirow[t]{2}{*}{ Shaw A.T. et al/2013 } & III & 347 & Crizotinib 500mg bid po & 51 & 7.7 & 20.3 & 172 \\
\hline & & & Chemotherapy & 49 & 3 & 22.8 & 171 \\
\hline Shaw A.T. et al/2014 & $\begin{array}{c}\text { Expansion } \\
\text { cohort }\end{array}$ & 81 & Ceritinib 750mg qd po & 53 & NR & NR & 81 \\
\hline \multirow[t]{2}{*}{ Solomon B.J. et al/2014 } & III & 343 & Crizotinib 500mg bid po & 52 & 10.9 & NR & 171 \\
\hline & & & Chemotherapy & 54 & 7 & NR & 169 \\
\hline Shaw A.T. et al/2016 & II & 87 & Alectinib $600 \mathrm{mg}$ bid po & 54 & NR & NR & 87 \\
\hline Kim D.W. et al/2016 & $\begin{array}{l}\text { Expansion } \\
\text { cohort }\end{array}$ & 255 & Ceritinib 750mg qd po & NR & NR & NR & 255 \\
\hline \multirow[t]{2}{*}{ Soria J.C. et al/2017 } & III & 376 & Ceritinib 750mg qd po & 55 & 16.6 & NR & 189 \\
\hline & & & Chemotherapy & 54 & 8.1 & NR & 175 \\
\hline
\end{tabular}

Abbreviations: PFS, progression-free survival; OS, overall survival; NR, not reported.

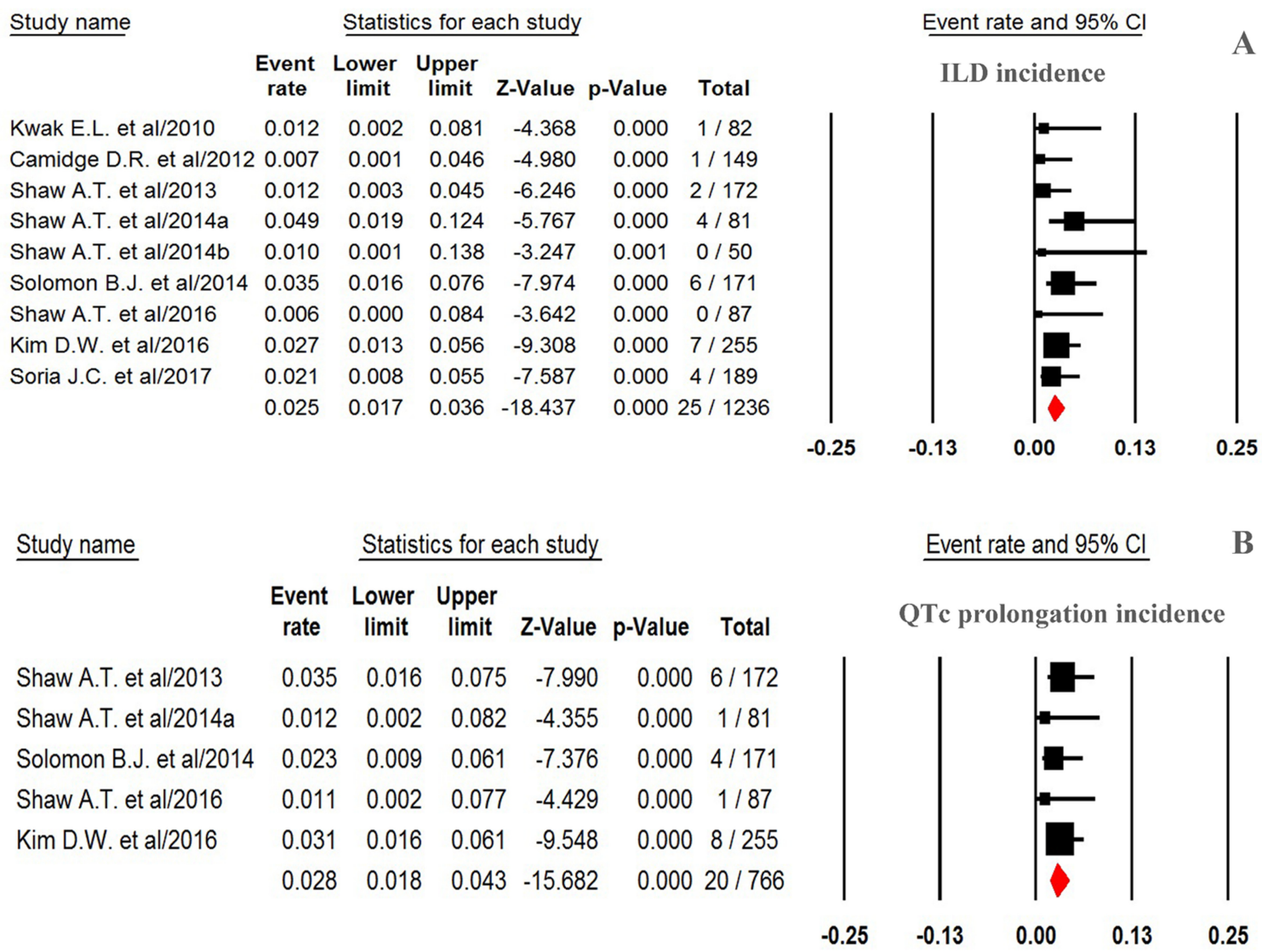

Figure 2: Forest plot for meta-analysis of incidence of high-grade ILD and QTe prolongation in NSCLC patients assigned ALK-TKIs. 


\section{Publication bias}

We did not perform publication bias analysis due to limited randomized controlled trials in the present study.

\section{DISCUSSION}

Recently, as the number of patients receiving new generations of tyrosine kinase inhibitors increase, TKIs associated ILD and QTc prolongation is being more commonly seen in clinical trials. Clinicians pay more and more attention to the risk of pulmonary and cardiac toxicities associated with these drugs. Two previous metaanalyses have found that the use of EGFR-TKIs (gefitinib and erlotinib) in advanced NSCLC significantly increases the risk of developing both all-grade and fatal ILD events $[23,24]$. Additionally, increased risk of drug-induced QTc prolongation has been also reported with vascular endothelial growth factor receptor (VEGFR) tyrosine kinase inhibitors (TKIs) [25, 26]. However, to our best knowledge, the overall incidence and risk of ILD and QTc prolongation associated with ALK-TKIs remains undetermined.

The present study has shown that the use of ALKTKIs are associated with a significantly increased risk of developing high-grade ILD and QTc prolongation. The incidences of high-grade ILD and QTc prolongation is $2.5 \%$ (95\% CI $1.7-3.6 \%$ ), and $2.8 \%$ (95\% CI $1.8-4.3 \%$ ), respectively. In comparison with chemotherapy alone, the use of ALK-TKIs significantly increases the risk of highgrade ILD (Peto OR, 3.27, 95\%CI: 1.18-9.08, $p=0.023$ ) and QTc prolongation (Peto OR 7.51, 95\% CI, 2.16$26.15 ; p=0.002$ ), respectively. A total of four patients permanently discontinued as a result of crizotinib-related pneumonitis, and three fatal ILD related with crizotinib were reported in these trials. In addition, seven patients in the ceritinib group had interstitial lung disease, resulting in permanent discontinuation of ceritinib treatment, and two fatal ILD with ceritinib were reported in our trials. The present study would help physicians and patients to fully recognize the overall risk of ILD and QTc prolongation with ALK-TKIs therapy in NSCLC patients. In order to reduce morbidity and mortality with ILD and QTc prolongation during the administration of ALK-TKIs, physicians should clearly recognize these risks and should pay close monitoring to ILD and QTc prolongation in NSCLC patients receiving ALK-TKIs.

Currently, the specific mechanism underlying TKIinduced ILD is undetermined. A previous research found that the EGFR signaling pathway play an important role in impairing lung epithelium [27]. As a result, inhibition of this signaling pathway might lead to EGFR-TKI-induced ILD.

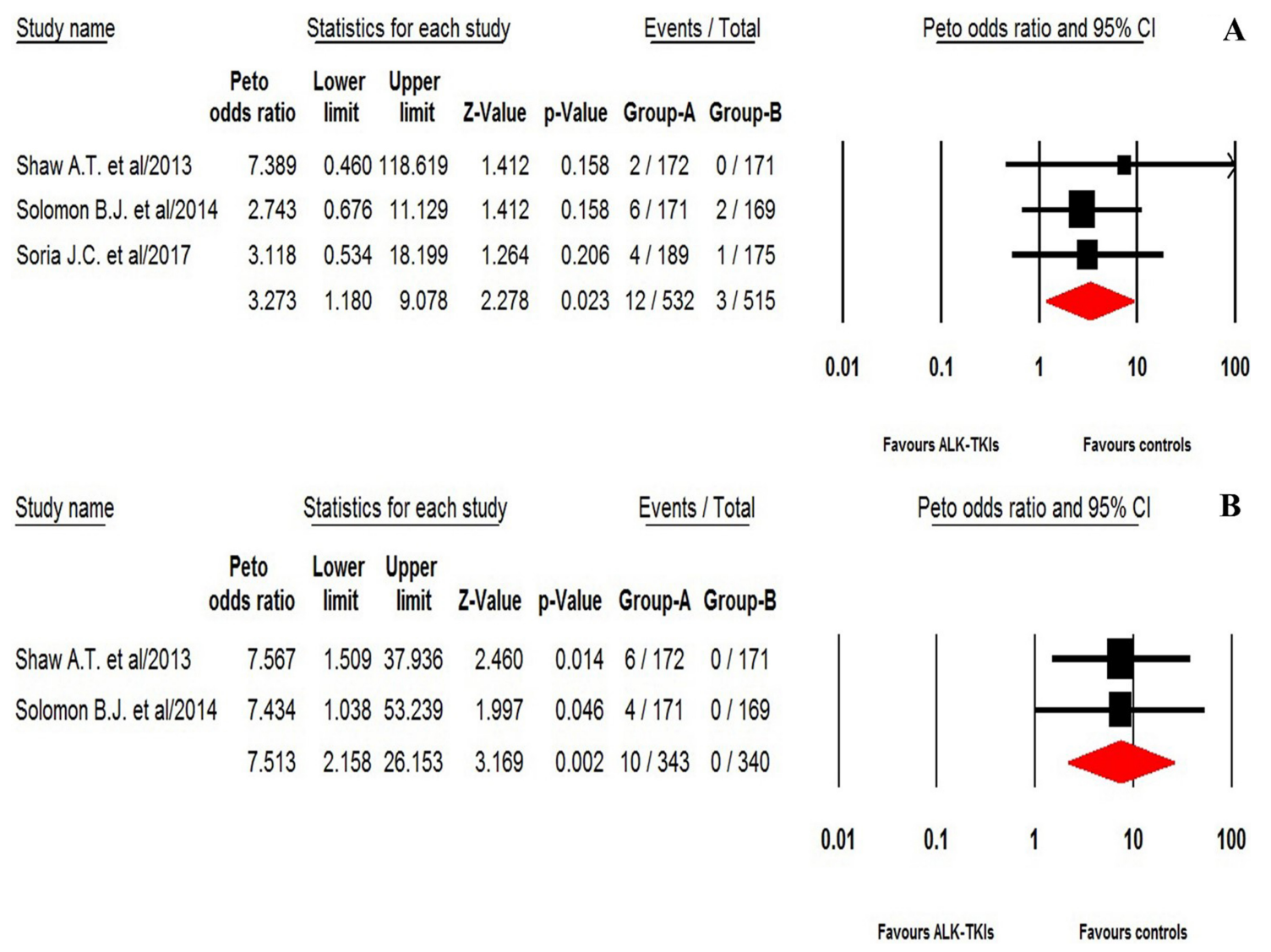

Figure 3: Relative risk of ALK-TKIs-associated high-grade ILD and QTe prolongation from randomized controlled trials. 
However, these is little knowledge about the mechanism of ALK-TKI related ILD. Currently, these are no specific guidelines for the treatment of ALK-TKIs-related ILD because these is lack of studies addressing this issues. The packet insert recommends that patients should be monitored for pulmonary symptoms indicative of ILD, and ALK-TKIs should be permanently discontinued for patients diagnosed with a drug-related ILD. Although systemic corticosteroids are often recommended and administered for drug-induced ILD, an effect of systemic corticosteroid administration on survival is not found. However, the relatively small sample size and retrospective nature of the present review do not allow us to rule out a potential benefit.

Cardiac toxicity by $\mathrm{I}_{\mathrm{Kr}}$ channel inhibition could be another major liability for some classes of novel targeted drugs. During preclinical drug development, some promising drugs could be abandoned due to the detection of $\mathrm{I}_{\mathrm{Kr}}$ channel inhibition or in vivo QT prolongation. The specific mechanism underlying TKIrelated QTc prolongation is thought to be associated with a drug's three-dimensional molecular structure, which could interact with myocardial hEGR $\mathrm{K}^{+}$channels. In addition, preclinical studies have found that ALK-TKIs could inhibit the ion channel which might be associated with delayed-rectifier $\mathrm{K}+$ current in the heart. Inhibition of the $\mathrm{I}_{\mathrm{Kr}}$ channel can result in QTc prolongation, which can lead to life-threatening cardiac toxicities [28]. According to the packet insert, ALK-TKIs should be immediately discontinued once drug-induced high-grade QTc prolongation occurs. The subsequent treatment has to be carefully considered if the patient recovery from the QTc prolongation, Additionally, routine EKG monitoring are recommended to be performed in patients receiving ALK-TKIs due to its increased risk of developing severe QTc prolongation.

Our meta-analysis has several limitations. Firstly, ILD is a complex disease encompassing many different pathological diseases. Also, the diagnostic criteria for ILD varies among included studies. Additionally, these studies are conducted at various centers, and the ability to detect ILD events might vary among these institutions, which could have potential bias in reporting incidence rates of ILD. Second, our study is a meta-analysis of published studies, but not a meta-analysis of individual patient data, and confounding factors at the patient level cannot be properly investigated in our study. Finally, publication bias is an important issue in the meta-analysis. We do not perform analysis to detect the publication bias due to limited included study for analysis.

\section{MATERIALS AND METHODS}

\section{Clinical end point}

The following adverse outcomes, including interstitial lung disease, pneumonitis, and interstitial pneumonia, were considered as ILD events and were included for analysis.

As for high-grade QTc prolongation, grade 3 QTc prolongation defined as QTc $\geq 501 \mathrm{~ms}$ and grade 4 QTc prolongation were included for analysis in the present study. Adverse events were defined as per version of the National Cancer Institute's Common Terminology Criteria for Adverse Events criteria because of its use in the selected trials (NCI-CTC, version 3 or 4; http://ctep.cancer.gov).

\section{Data sources}

We conducted an independent review of citations in several databases, including the Pubmed (data from Jan 2000 to Jan 2017), Embase (data from Jan 2000 to Jan 2017) and the Cochrane Library. Key words were "ALK-TKIs", "ALK inhibitors", "crizotinib", "ceritinib", “alectinib”, "non-small-cell lung cancer", "non-small-cell lung carcinoma", "prospective trials", "interstitial lung disease", "pneumonitis", "interstitial pneumonia", and "QTc prolongation". The search was limited to prospective clinical trials published in English. We also searched abstracts containing the term "ALK-TKIs" that were presented at annual meetings to identify relevant studies, including the American Society of Clinical Oncology (ASCO) and European Society of Medical Oncology (ESMO). Additionally, we searched the clinical trial registration website (http://www.ClinicalTrials.gov) to obtain information on the registered prospective trials. Each publication was reviewed and in cases of duplicate publication only the most complete, recent, and updated report of the clinical trial was included in the meta-analysis.

\section{Study selection}

Phase I trials were excluded because of inter study variability in drug dosing and the limited sample sizes, and only prospective phase II/III trials evaluating ALKTKIs in NSCLC patients with adequate data on toxicities of special interest were incorporated in the analysis. Study selection was conducted according the Preferred Reporting Items for Systematic Reviews and MetaAnalyses (PRISMA) statement. Clinical trials that met the following criteria were included: (1) prospective phase II or III trials involving NSCLC patients; and (2) available data regarding events or incidence of ILD events/QTc prolongation and sample size. If multiple publications of the same trial were retrieved or if there was a case mix between publications, only the most recent publication (and the most informative) was included.

\section{Data extraction}

Two independent investigators conducted the data abstraction, and any discrepancy between the reviewers was resolved by consensus. The following information 
was extracted for each study: first author's name, year of publication, trial phase, number of enrolled subjects, treatment arms, number of patients in treatment and controlled groups, median age, median progression-free survival, and adverse outcomes of interest (high-grade ILD and QTc prolongation).

\section{Statistical analysis}

The primary summary measures were incidence, Peto odds ratios (ORs), and corresponding 95\%CIs. All statistical analyses were performed by using Version 2 of the Comprehensive MetaAnalysis program (Biostat, Englewood, NJ). For the calculation of incidence, the number of patients with high-grade ILD and QTc prolongation in ALK-TKIs group and the total number of patients receiving ALK-TKIs were extracted; the proportion of patients with high-grade ILD and QTc prolongation and 95\% confidence interval (CI) were derived for each study. To calculate Peto ORs, patients assigned to ALK-TKIs were compared only with those assigned to control treatment in the same trial. We used the Peto method to calculate odds ratio (ORs) and 95\%CI confidence intervals (CIs) because this method provided the best confidence interval coverage when dealing with low event rates [29]. Between-study heterogeneity was estimated using the $\chi^{2}$-based Q statistic [30]. The $I^{2}$ statistic was also calculated to evaluate the extent of variability attributable to statistical heterogeneity between trials. A statistical test with a $p$-value less than 0.05 was considered significant. Study quality was assessed by using the Jadad scale based on the reporting of the studies' methods and results [31].

\section{CONCLUSIONS}

In summary, the present study has found that the use of ALK-TKIs significantly increases the risk of developing high-grade ILD and QTc prolongation. Clinicians should be aware of the risks and benefits with ALK-TKIs treatment in NSCLC patients. Finally, further research are still needed to clearly investigate the predictive factors of these toxicities with administration of ALK-TKIs treatment.

\section{Abbreviations}

anaplastic lymphoma kinase:ALK; tyrosine kinase inhibitors:TKIs; non-small cell lung cancer: NSCLC; Interstitial lung disease:ILD; Peto odds ratios:Peto ORs; confidence intervals:CIs; Food and Drug Administration:FDA; vascular endothelial growth factor receptor:VEGFR.

\section{CONFLICTS OF INTEREST}

All authors declare that they have no potential conflicts of interests.

\section{FUNDING}

This work is funded by Guangzhou Medicines and Health science and Technology Project (N0.20141A010102)

\section{REFERENCES}

1. Jemal A, Bray F, Center MM, Ferlay J, Ward E, Forman D. Global cancer statistics. CA Cancer J Clin. 2011; 61:69-90.

2. Herbst RS, Heymach JV, Lippman SM. Lung cancer. N Engl J Med. 2008; 359:1367-1380.

3. Metro G, Tazza M, Matocci R, Chiari R, Crino L. Optimal management of ALK-positive NSCLC progressing on crizotinib. Lung Cancer. 2017; 106:58-66.

4. Cameron L, Solomon B. New Treatment Options for ALK-Rearranged Non-Small Cell Lung Cancer. Curr Treat Options Oncol. 2015;16:49.

5. Giaccone G, Herbst RS, Manegold C, Scagliotti G, Rosell R, Miller V, Natale RB, Schiller JH, Von Pawel J, Pluzanska A, Gatzemeier U, Grous J, Ochs JS, et al. Gefitinib in combination with gemcitabine and cisplatin in advanced non-small-cell lung cancer: a phase III trial-INTACT 1. J Clin Oncol. 2004; 22:777-784.

6. Herbst RS, Prager D, Hermann R, Fehrenbacher L, Johnson BE, Sandler A, Kris MG, Tran HT, Klein P, Li X, Ramies D, Johnson DH, Miller VA. TRIBUTE Investigator Group. TRIBUTE: a phase III trial of erlotinib hydrochloride (OSI-774) combined with carboplatin and paclitaxel chemotherapy in advanced non-small-cell lung cancer. J Clin Oncol. 2005; 23:5892-5899.

7. Barlesi F, Mazieres J, Merlio JP, Debieuvre D, Mosser J, Lena H, Ouafik L, Besse B, Rouquette I, Westeel V, Escande F, Monnet I, Lemoine A, et al. Routine molecular profiling of patients with advanced non-small-cell lung cancer: results of a 1-year nationwide programme of the French Cooperative Thoracic Intergroup (IFCT). Lancet. 2016; 387:1415-1426.

8. Kazandjian D, Blumenthal GM, Chen HY, He K, Patel M, Justice R, Keegan P, Pazdur R. FDA approval summary: crizotinib for the treatment of metastatic non-small cell lung cancer with anaplastic lymphoma kinase rearrangements. Oncologist. 2014; 19:e5-11.

9. Rossi A. Alectinib for ALK-positive non-small-cell lung cancer. Expert Rev Clin Pharmacol. 2016; 9:1005-1013.

10. Nukaga S, Naoki K, Kamo T, Masuzawa K, Yasuda H, Soejima K, Betsuyaku T. Alectinib as a treatment option following recovery from crizotinib-induced interstitial lung disease in patients with anaplastic lymphoma kinase-positive advanced non-small-cell lung cancer. Molecular and clinical oncology. 2016; 4:1085-1087.

11. Khozin S, Blumenthal GM, Zhang L, Tang S, Brower M, Fox E, Helms W, Leong R, Song P, Pan Y, Liu Q, Zhao P, Zhao $\mathrm{H}$, et al. FDA approval: ceritinib for the treatment of 
metastatic anaplastic lymphoma kinase-positive non-small cell lung cancer. Clin Cancer Res. 2015; 21:2436-2439.

12. Loong HH, Mok K, Leung LK, Mok TS. Crizotinib in the management of advanced-stage non-small-cell lung cancer. Future Oncol. 2015; 11:735-745.

13. Solomon B, Wilner KD, Shaw AT. Current status of targeted therapy for anaplastic lymphoma kinase-rearranged non-small cell lung cancer. Clinical pharmacology and therapeutics. 2014; 95:15-23.

14. Rothenstein JM, Letarte N. Managing treatment-related adverse events associated with Alk inhibitors. Curr Oncol. 2014; 21:19-26.

15. Shaw AT, Kim DW, Nakagawa K, Seto T, Crinó L, Ahn MJ, De Pas T, Besse B, Solomon BJ, Blackhall F, Wu YL, Thomas M, O'Byrne KJ, et al. Crizotinib versus chemotherapy in advanced ALK-positive lung cancer. N Engl J Med. 2013; 368:2385-2394.

16. Solomon BJ, Mok T, Kim DW, Wu YL, Nakagawa K, Mekhail T, Felip E, Cappuzzo F, Paolini J, Usari T, Iyer S, Reisman A, Wilner KD, et al. First-line crizotinib versus chemotherapy in ALK-positive lung cancer. N Engl J Med. 2014; 371:2167-2177.

17. Soria JC, Tan DS, Chiari R, Wu YL, Paz-Ares L, Wolf J, Geater SL, Orlov S, Cortinovis D, Yu CJ, Hochmair M, Cortot $\mathrm{AB}$, Tsai $\mathrm{CM}$, et al. First-line ceritinib versus platinum-based chemotherapy in advanced ALK-rearranged non-small-cell lung cancer (ASCEND-4): a randomised, open-label, phase 3 study. Lancet. 2017; 389:917-929.

18. Kwak EL, Bang YJ, Camidge DR, Shaw AT, Solomon B, Maki RG, Ou SH, Dezube BJ, Jänne PA, Costa DB, VarellaGarcia M, Kim WH, Lynch TJ, et al Anaplastic lymphoma kinase inhibition in non-small-cell lung cancer. N Engl J Med. 2010; 363:1693-1703.

19. Camidge DR, Bang YJ, Kwak EL, Iafrate AJ, VarellaGarcia M, Fox SB, Riely GJ, Solomon B, Ou SH, Kim DW, Salgia R, Fidias P, Engelman JA, et al. Activity and safety of crizotinib in patients with ALK-positive non-small-cell lung cancer: updated results from a phase 1 study. Lancet Oncol. 2012; 13:1011-1019.

20. Shaw AT, Kim DW, Mehra R, Tan DS, Felip E, Chow LQ, Camidge DR, Vansteenkiste J, Sharma S, De Pas T, Riely GJ, Solomon BJ, Wolf J, et al. Ceritinib in ALKrearranged non-small-cell lung cancer. N Engl J Med. 2014; 370:1189-1197.

21. Kim DW, Mehra R, Tan DS, Felip E, Chow LQ, Camidge DR, Vansteenkiste J, Sharma S, De Pas T, Riely GJ, Solomon BJ, Wolf J, Thomas M. et al. Activity and safety of ceritinib in patients with ALK-rearranged non-small- cell lung cancer (ASCEND-1): updated results from the multicentre, open-label, phase 1 trial. Lancet Oncol. 2016; $17: 452-463$.

22. Shaw AT, Gandhi L, Gadgeel S, Riely GJ, Cetnar J, West H, Camidge DR, Socinski MA, Chiappori A, Mekhail T, Chao BH, Borghaei H, Gold KA. et al. Alectinib in ALKpositive, crizotinib-resistant, non-small-cell lung cancer: a single-group, multicentre, phase 2 trial. Lancet Oncol. 2016; 17:234-242.

23. Qi WX, Sun YJ, Shen Z, Yao Y. Risk of interstitial lung disease associated with EGFR-TKIs in advanced non-smallcell lung cancer: a meta-analysis of 24 phase III clinical trials. Journal of chemotherapy. 2015; 27:40-51.

24. Shi L, Tang J, Tong L, Liu Z. Risk of interstitial lung disease with gefitinib and erlotinib in advanced non-small cell lung cancer: a systematic review and meta-analysis of clinical trials. Lung Cancer. 2014; 83:231-239.

25. Ghatalia P, Je Y, Kaymakcalan MD, Sonpavde G, Choueiri TK. QTc interval prolongation with vascular endothelial growth factor receptor tyrosine kinase inhibitors. Br J Cancer. 2014.

26. Zang J, Wu S, Tang L, Xu X, Bai J, Ding C, Chang Y, Yue L, Kang E, He J. Incidence and risk of QTc interval prolongation among cancer patients treated with vandetanib: a systematic review and meta-analysis. PLoS One. 2012; 7:e30353.

27. Harada C, Kawaguchi T, Ogata-Suetsugu S, Yamada M, Hamada N, Maeyama T, Souzaki R, Tajiri T, Taguchi T, Kuwano K, Nakanishi Y. EGFR tyrosine kinase inhibition worsens acute lung injury in mice with repairing airway epithelium. American journal of respiratory and critical care medicine. 2011; 183:743-751.

28. Shopp GM, Helson L, Bouchard A, Salvail D, Majeed M. Liposomes ameliorate Crizotinib- and Nilotinib-induced inhibition of the cardiac IKr channel and QTc prolongation. Anticancer Res. 2014; 34:4733-4740.

29. Sweeting MJ, Sutton AJ, Lambert PC. What to add to nothing? Use and avoidance of continuity corrections in meta-analysis of sparse data. Stat Med. 2004; 23:13511375.

30. Zintzaras E, Ioannidis JP. Heterogeneity testing in metaanalysis of genome searches. Genet Epidemiol. 2005; 28:123-137.

31. Moher D, Pham B, Jones A, Cook DJ, Jadad AR, Moher M, Tugwell P, Klassen TP. Does quality of reports of randomised trials affect estimates of intervention efficacy reported in meta-analyses? Lancet. 1998; 352:609-613. 